Military Technical College Kobry El-Kobbah, Cairo, Egypt

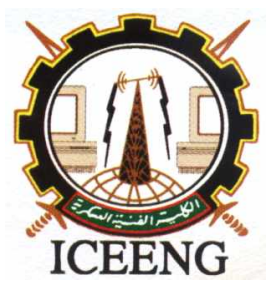

\author{
$6^{\text {th }}$ International Conference \\ on Electrical Engineering \\ ICEENG 2008
}

\title{
Estimation of optimum load and thermal response for Oil-Natural-Air- Natural cooling type power transformer
}

$$
\text { By }
$$
S.S. Ngu*
H.S. Thye *
L.C.Kho*
K.P. Leslie Chai **
S.K. Kee**
O.M. Shahril *

\section{Abstract:}

This paper described the estimation of optimum load and thermal response for the Oilnatural Air-natural (ONAN) cooling type power transformer with installed load capacity of 30MVA in Sarawak, Malaysia. The estimation optimum load capacity is based on the nameplate rating, standard design of the existing transformer and factory acceptance test report (FAT). This involved loss of life and transformer thermal response such as hotspot temperature, top-oil temperature, winding temperature and ambient temperature. By using the existing cyclic load of this transformer, the risk condition of the transformer could be prevented since capacity load could be estimated. The algorithms of this project were based on IEEE standard and IEC loading guide for oil-immersed power transformer.

\section{Keywords:}

Thermal response, optimum load capacity, hot spot temperature.

* Universiti Malaysia Sarawak

** Sarawak Electricity Supply Corporation (SESCo) 


\section{Introduction:}

The transformer's cyclic load profile could be used to estimate the transformer life and the maximum winding hot spot temperature rise occurred inside the insulator. Most of the power suppliers were interest in the transformer life expectancy and insulator temperature. The influence of hot spot temperature rise could affect the Degraded Polymerization (DP) of the oil insulator. Limitation of the load occurs in order to avoid the bubble generated and reduced the weakness of the dielectric. Stability and reliability of the performance in this transformer influences due to this tragedy. To obtain the optimum load without harm to the transformer's life, the rated value in nameplate used. IEEE and IEC loading guide for oil-immersed power transformer standard were used [1, $2,3,4$, and 5].

\section{Transformer Thermal response models:}

In the analysis of the ONAN cooling type power transformer, the parameters obtained were shown in Table 1. These parameters are useful in order to obtain precise thermal response.

Besides, the load profile was needed in this case for the estimation of the optimum load capacity and transformer thermal response. Heat generated depends on the daily load profile which is the reactive power losses from the coil.

The time interval of the daily load profile and the top oil temperature rise in steady state condition must be determined in order to estimate real time maximum top oil temperature rise. The duration of the maximum top oil temperature rise which is the top oil time constant in hour is given by the following formula;

$\tau_{T O, R}=\frac{C \times \Delta \Theta_{T O, R}}{p_{T, R}}$

Where the thermal capacity for the ONAN cooling type transformer is determined as following formula;

$$
\begin{aligned}
C= & 0.1322 \text { (Weight of core and coil assembly) } \\
& +0.0882 \text { (Weight of tank and fittings) } \\
& +0.3513 \text { (Liters of oil) }
\end{aligned}
$$




\section{Table (1): Transformer parameters}

\begin{tabular}{|l|l|}
\hline \multicolumn{1}{|c|}{ Parameters } & \multicolumn{1}{c|}{ Value } \\
\hline No-load losses & $10.98 \mathrm{~kW}$ \\
\hline Load losses & $122.91 \mathrm{~kW}$ \\
\hline Ratio load losses to no-load losses at rated kVA, $\mathrm{R}$ & 11.1940 \\
\hline Top oil temperature at rated kVA, & $60^{\circ} \mathrm{C}$ \\
\hline Winding temperature at rated kVA & $25.09^{\circ} \mathrm{C}$ \\
\hline Weight of core and coil assembly & $27750 \mathrm{~kg}$ \\
\hline Weight of tank and fittings & $34250 \mathrm{~kg}$ \\
\hline Liters of oil & $17.75 \ell$ \\
\hline ONAN Exponent parameter, $m$ & 0.8 \\
\hline ONAN Exponent parameter, $n$ & 0.8 \\
\hline Interval time, $t$ & $0.5 \mathrm{~h}$ \\
\hline Total load losses & $144.66 \mathrm{~kW}$ \\
\hline
\end{tabular}

\subsection{Top Oil Temperature Rise Over Ambient:}

The ultimate top oil temperatures rise over ambient temperature is given as below;

$\Delta \Theta o u=\Delta \Theta_{T O, R}\left(\frac{1+R K^{2}}{1+R}\right)^{n}$

Where the initial top oil temperatures rise over ambient temperature is given as following formula;

$\Delta \Theta o i=\Delta \Theta_{T o, R}\left(\frac{1+R K^{2}}{1+R}\right)^{n}$

The top oil temperature rise is the differential of the ultimate and initial top oil temperature with the exponents factor which is given in the formula;

$$
\Delta \Theta_{T O}=\Delta \Theta o i+(\Delta \Theta o u-\Delta \Theta o i)\left(1-\exp \left(\frac{-t}{\tau_{T O, R}}\right)\right)
$$




\subsection{Winding Hottest Spot Temperature rise:}

Transient winding hottest spot temperature rise over top oil temperature is given by;

$$
\Delta \Theta_{H}=\Delta \Theta_{H, R} K^{2 m}
$$

\subsection{Hot Spot Temperature:}

The hot spot temperature could be obtained from the summation of top oil temperature rise, winding hottest spot temperature rise and ambient temperature. This equation is shown below;

$\Theta h=\Theta a+\Delta \Theta_{T O}+\Delta \Theta_{H}$

\subsection{Aging Acceleration Factor:}

For the equation of an aging acceleration factor $\left(\mathrm{F}_{\mathrm{AA}}\right)$ for a given load and temperature or for a varying load and temperature profile over a 24 hours period as follows;

$F_{A A}=\exp \left(\frac{15000}{383}-\frac{15000}{\Theta h+273}\right)$

\subsection{Loss of Life:}

Percent loss of insulation life in the time period is equivalent hours life consumed divided by the definition of total normal insulation life (hours) and multiplied by 100 . The equation is given as follows;

$\% L O L=\frac{F_{E Q A} \times 24}{\text { Normal Insulation Life }} \times 100$

Where normal insulation life is $219000 \mathrm{~h}$ (25 years) and $F_{E Q A}$ is equivalent aging factor for the total time period is given by equation below;

$$
F_{E Q A}=\frac{\sum_{n=1}^{24} F_{A A n} \Delta t_{n}}{\sum_{n=1}^{24} \Delta t_{n}}
$$




\subsection{Results:}

Thermal response of the ONAN cooling type with $30 \mathrm{MVA}, 33 / 11 \mathrm{kV}$ transformer where tested by using the parameters and the methodology above. Daily equivalent load of this transformer where taken as shown in Figure 1. From the experiment, the peak load obtained is $0.403928 \mathrm{p} . \mathrm{u}$ fall between 8.04 to 9.01 hours. Table 2 shows the daily equivalent load. Therefore the optimum load for this daily load is 0.403928 which is equal to $12.11784 \mathrm{MVA}$. The optimum capacity load could be overloaded below the 1.20p.u.

Table (2):The duration of the daily equivalent load

\begin{tabular}{|l|l|}
\hline Time /hour & Load/per unit \\
\hline 0 to 8 & 0.183095 \\
\hline 8.04 to 9.01 & 0.403928 \\
\hline 9.02 to 24 & 0.183095 \\
\hline
\end{tabular}

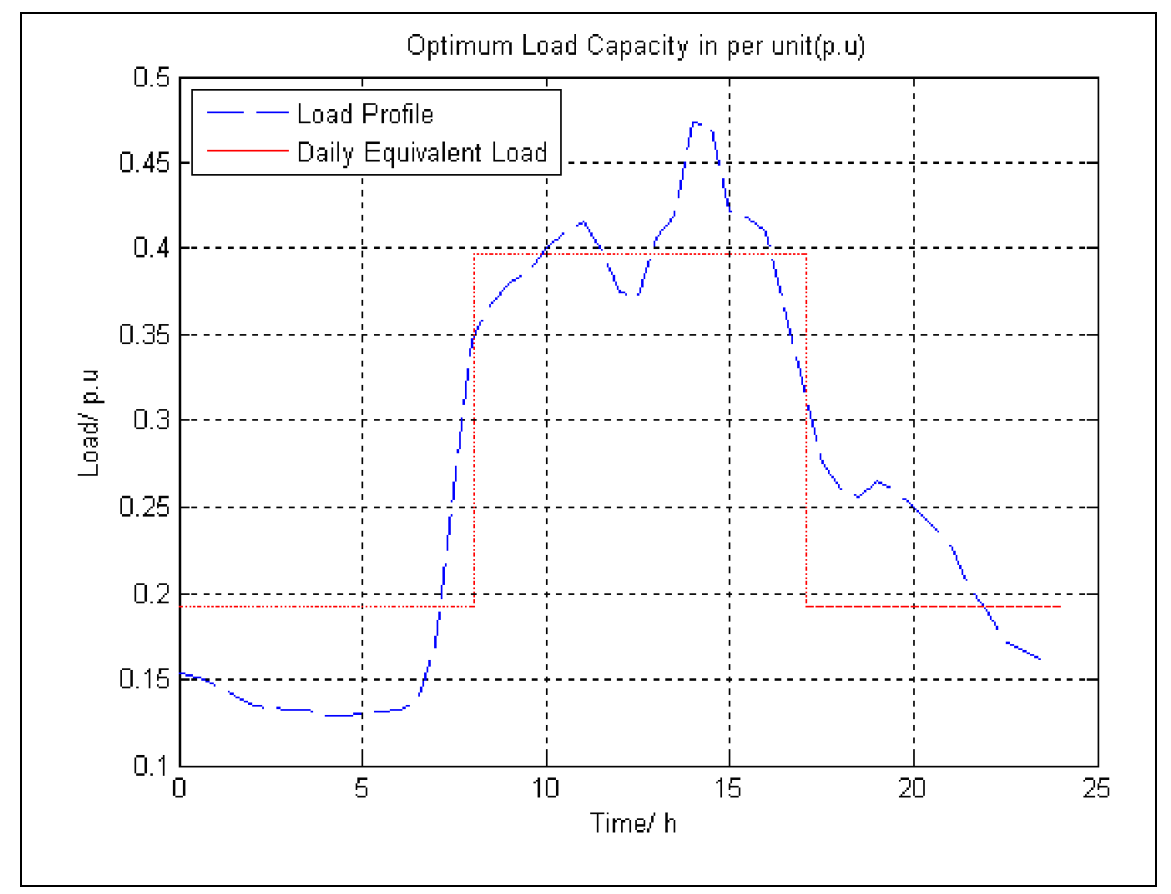

Figure (1): Load profile with the one cycle Daily Equivalent Load

Average ambient where taken by measured $1 \mathrm{~m}$ length from the back side, rear side, left and right side of the transformer. Although the range of the temperature is in the range of $23^{\circ} \mathrm{C}$ to $34^{\circ} \mathrm{C}$, the average ambient temperature obtain is $30^{\circ} \mathrm{C}$ for duration of 24 hour. 
The hottest-spot temperatures were $55.48^{\circ} \mathrm{C}$ and $54.13^{\circ} \mathrm{C}$ for the IEEE method and IEC method correspondingly. Figure 2 and Figure 3 shows the thermal response based on IEEE and IEC. Mean square error (MSE) of the top oil temperature measurement and method is acceptable with 3.8079. In other meaning that, this is very accurate and precise. However, the MSE of the IEC method is still acceptable with value of 7.9615.

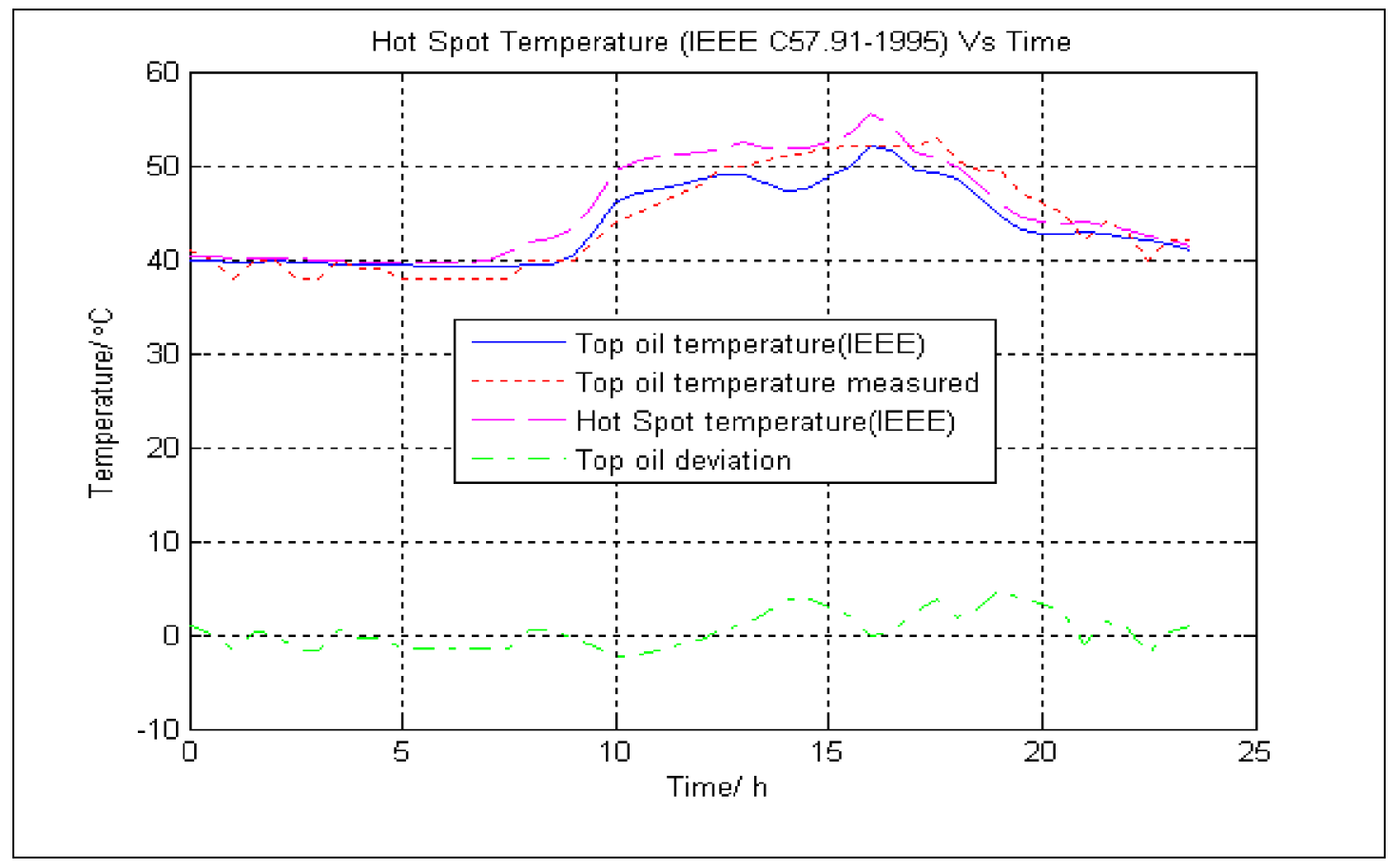

Figure (2): Thermal response based on IEEE

Table 3 show the maximum and minimum deviation of the top oil temperature. The deviation patterns were shows in the Figure 2 and Figure 3.

Aging acceleration factor for both standard were shown in Figure 4 and Figure 5. Non losses of life occur in this type of load.

\section{Table (3): Deviation of the top oil temperature}

\begin{tabular}{|l|l|l|}
\hline \multirow{2}{*}{} & \multicolumn{2}{|c|}{ Temperature } \\
\cline { 2 - 3 } & \multicolumn{1}{|c|}{$($ IEEE) } & \multicolumn{1}{c|}{ (IEC) } \\
\hline Hottest Spot temperature & $55.4831^{\circ} \mathrm{C}$ & $54.1302^{\circ} \mathrm{C}$ \\
\hline Maximum Deviation & $4.8836^{\circ} \mathrm{C}$ & $6.8362^{\circ} \mathrm{C}$ \\
\hline Minimum Deviation & $-2.2319^{\circ} \mathrm{C}$ & $-2.9364^{\circ} \mathrm{C}$ \\
\hline Mean Square Error (MSE) & 3.8079 & 7.9615 \\
\hline
\end{tabular}




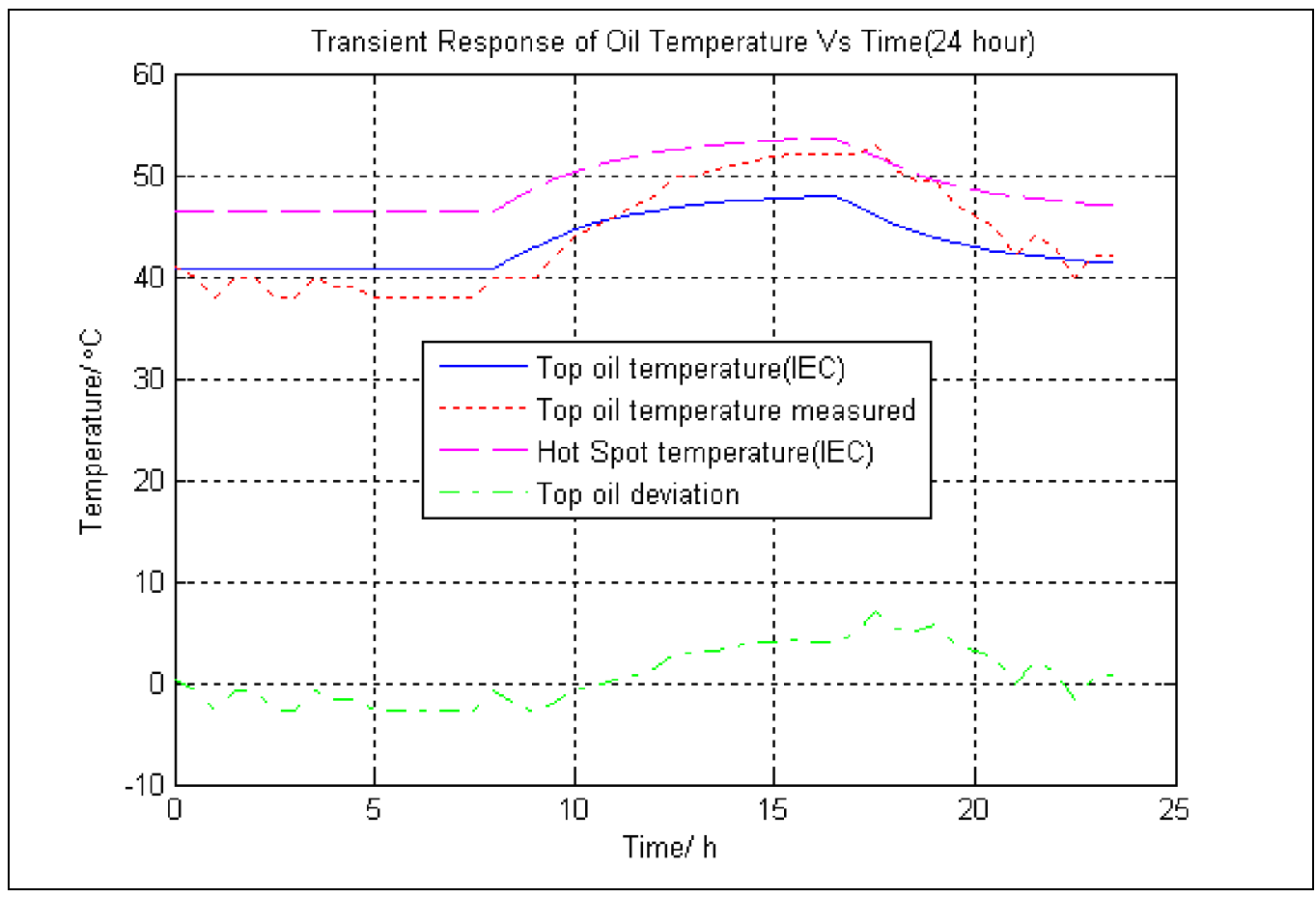

Figure (3): Thermal response based on IEC

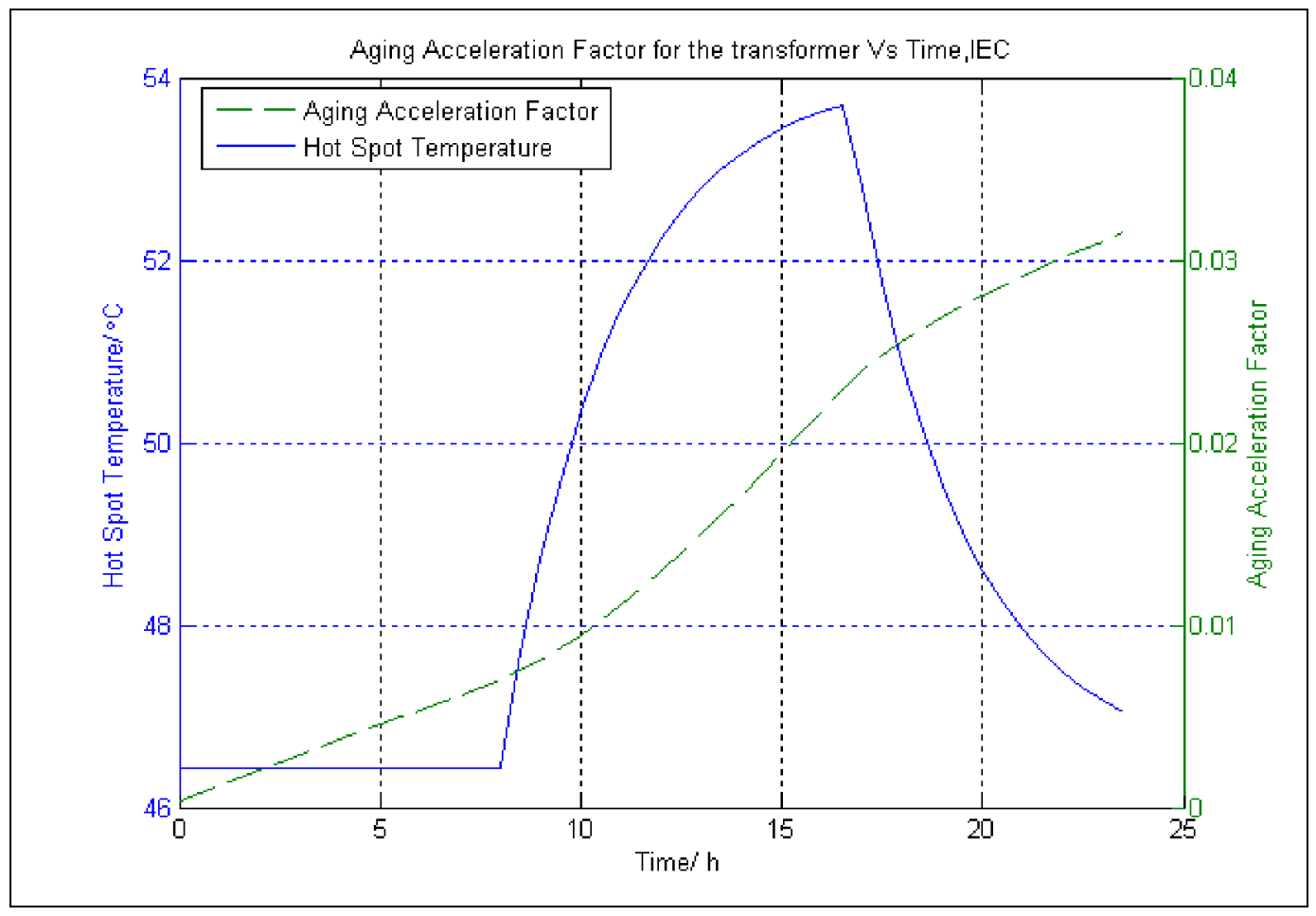

Figure (4): Aging acceleration factor based on IEC 


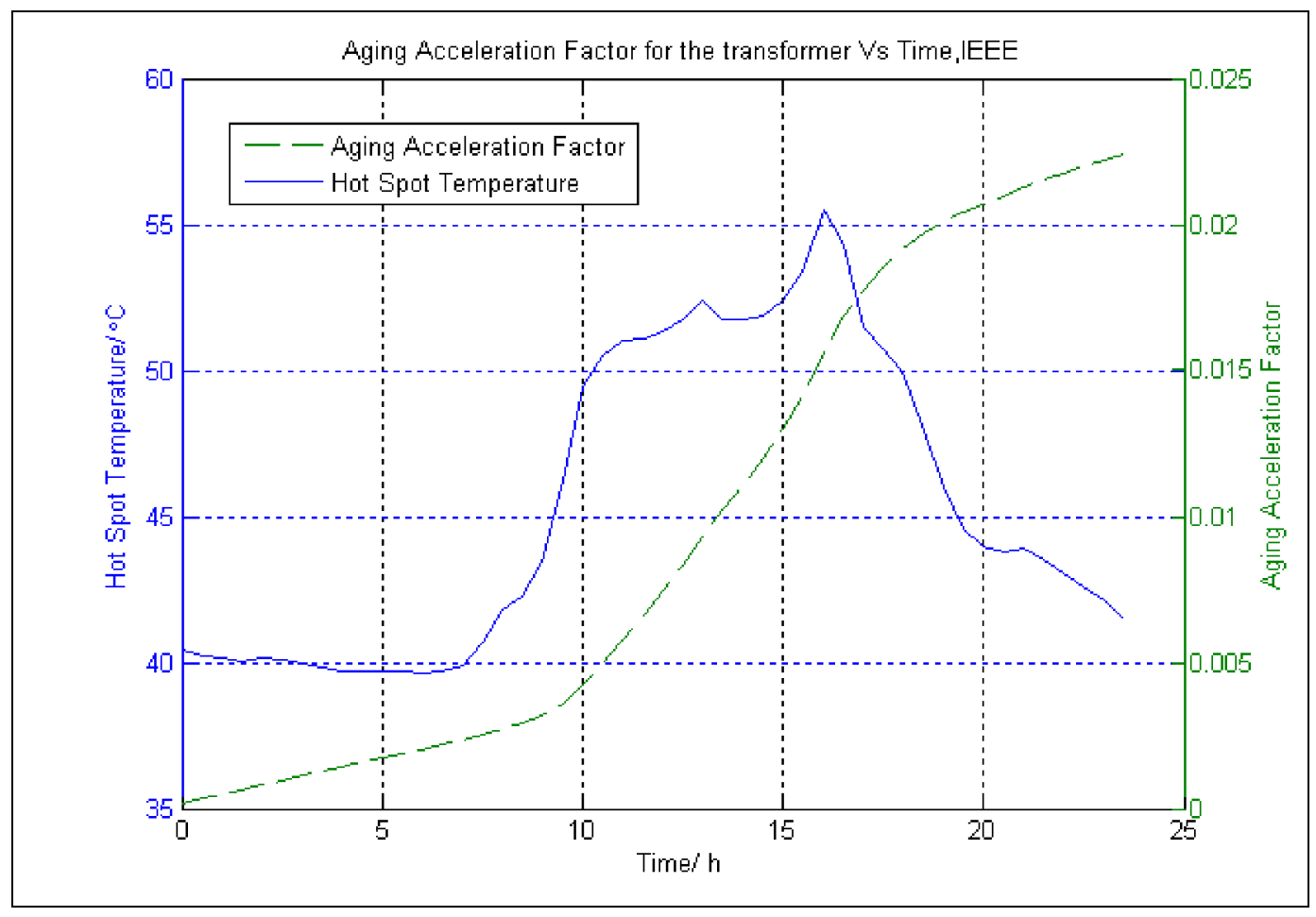

Figure (5): Aging acceleration factor based on IEEE

\subsection{Conclusion:}

As a conclusion, the mean square errors for both standards are acceptable. In other words, the estimation of the optimum load capacity and thermal response model is accurate and precise with the ambient temperature of $30^{\circ} \mathrm{C}$. There are non losses of life in this type of load due to the under load with below than 0.5p.u.

This model could be used in the thermal response notification and could use for the prediction for the planned load beyond nameplate (PBLN), short term emergency load (STE) and long term emergency load (LTE). The development of the prediction for the PBLN, STE and LTE will be carried out in future.

\section{References:}

[1] "IEEE standard C57.91-1995: IEEE Guide for Loading Mineral-Oil-Immersed Transformer". Jun 14, 1995.

[2] "IEEE standard C57.119-2001: IEEE Recommended Practice for Performing Temperature Rise Tests on Oil- Immersed Power Transformers at Loads Beyond Nameplate Ratings". March 12, 2002. 
[3] "Loading Guide for Loading Oil-Immersed Power Transformer, IEC Publication $354 " .1991$.

[4] "IEEE standard C57.91-1995/Cor 1-2002: IEEE Guide for Loading Mineral-OilImmersed Transformer Corrigendum 1". Jun 12, 2003.

[5] "IEC 76-2: Power transformer Part 2- Temperature rise", $2^{\text {nd }}$ Edition. 1993.

[6] J. O'Grady. "Overloading Power Transformers - a User's Views", Power Engineering Journal, pp. 87-93, Mar. 1990.

[7] "IEEE Std C57.12.90-1999: IEEE Standard Test Code for Liquid-Immersed Distribution, Power and Regulating Transformers". June 26, 1999.

[8] Carlson Ake, Fuhr Jitka, Schemel Gottfriend and Wegscheider Franz. $1^{\text {st }}$ Edition. October 2003. Testing of Power Transformers- Routine tests, Type tests and Special tests.

\section{Nomenclatures:}

$R$... Ratio load losses to no-load losses at rated $\mathrm{kVA}$

$K \ldots$ Load profile per unit

$\Delta \Theta_{T O, R} \ldots$ Top oil temperature at rated $\mathrm{kVA}$ in ${ }^{\circ} \mathrm{C}$

$\Delta \Theta_{H, R} \cdots$ Winding temperature at rated $\mathrm{kVA}$ in ${ }^{\circ} \mathrm{C}$

$\Delta \Theta о и$... Ultimate top oil temperature rise in ${ }^{\circ} \mathrm{C}$

$\Delta \Theta o i \ldots$ Initial top oil temperature rise in ${ }^{\circ} \mathrm{C}$

$\Theta a \ldots$ Ambient temperature in ${ }^{\circ} \mathrm{C}$

$\Delta \Theta_{T O} \ldots$ Top oil temperature in ${ }^{\circ} \mathrm{C}$

$\Delta \Theta_{H} \ldots$ Winding hottest-spot temperature rise in ${ }^{\circ} \mathrm{C}$

$\Theta h \ldots$ Hot-Spot temperature in ${ }^{\circ} \mathrm{C}$

$p_{T, R} \ldots$ Total power losses in $\mathrm{KW}$

$C \ldots$ Thermal Capacity in $\mathrm{W}-\mathrm{h} /{ }^{\circ} \mathrm{C}$

$\tau_{T O, R} \ldots$ Top oil time constant in hour

$t$... Time interval of the load in hour

$m$... Exponent parameter

$n$... Exponent parameter

$F_{A A} \ldots$ Aging Acceleration Factor

$F_{E Q A} \ldots$ Equivalent Aging Factor

$\% L O L \ldots$ Loss of Life in percentage 